Article

\title{
Improving Safety and Efficiency of Roundabouts Through an Integrated System of Guide Signs
}

\author{
Hongliang Wan ${ }^{1} \mathbb{D}$, Xiaohong Chen ${ }^{2, *}$ and Zhigang $\mathrm{Du}^{3, *}$ \\ 1 The Key Laboratory of Road and Traffic Engineering, Ministry of Education, College of Transportation \\ Engineering, Tongji University, Shanghai 201804, China; 1510702@tongji.edu.cn \\ 2 College of Transportation Engineering, Tongji University, Shanghai 201804, China \\ 3 School of Transportation, Wuhan University of Technology, Wuhan 430063, China \\ * Correspondence: chenxh@tongji.edu.cn (X.C.); zhigang_du@whut.edu.cn (Z.D.)
}

Received: 25 August 2019; Accepted: 20 September 2019; Published: 23 September 2019

\begin{abstract}
A roundabout can improve intersection capacity in some extent by reducing conflict points and traffic delays. However, the complex environment in a large roundabout does not provide essential directional information to motorists. Therefore, drivers must spend more time identifying the exit they want, which may influence the intersection capacity and safety. Using perceptual constancy, a new guide sign system for roundabouts was developed to improve sense of direction. In order to observe how the guide sign system would affect drivers' sense of direction, a series of driving simulator experiments were conducted to evaluate driving performance. The test results revealed that the guide sign system can effectively improve the accuracy of exit identification and reduce travel time driving through a roundabout despite the gender and age differences among drivers. This paper proposes a continuous and gradual guide sign system for roundabouts that can be used to help improve drivers' sense of direction, which is beneficial to improve the safety and efficiency of roundabout operations. These findings are indicative of the future development of traffic sign design and practice in a roundabout.
\end{abstract}

Keywords: roundabout; traffic design; traffic management; perceptual constancy; mental rotation

\section{Introduction}

Compared to other types of intersections, roundabouts have demonstrated multiple benefits such as improved traffic safety, pedestrian safety, and road capacity, as well as reduced congestion, pollution, and energy consumption [1,2]. Compact roundabouts also have traffic calming effects by reducing vehicle speeds using geometric design elements [3]. However, driving through a roundabout involves a more complicated decision-making process. Moreover, roundabouts in China are often constructed at large intersections. The complex environment in a large roundabout does not provide essential directional information to motorists. In other words, drivers must spend more time identifying the exit they want, which may decrease the operational efficiency of roundabouts. In order to improve sense of direction, a simple and low-cost method was proposed in this paper using traffic signs and pavement markings rather than relying only on road reconstruction.

Traffic signs and road markings provide essential information to road users, which guide motorists and regulate their driving behaviors [4]. With the installment of traffic signs and road markings, road traffic operates with safety, convenience, and efficiency. Countries all over the world have largely agreed on the principles for the design (shape, color, size, and layout) of traffic signs, but different parts of the world have applied different rules, which contribute to variations on signs and markings. Many studies have examined the effects of the various dimensions of traffic signs and road markings, such as background color [5], symbol and text mixture [6], visibility and legibility [7], and lighting 
criteria [8]. Moreover, the number of signs and road markings [9,10] and location selection [11,12] have also been widely studied. Another large body of research has explored factors associated with the correct comprehension of traffic signs and road markings [13-15]. Ng and Chan addressed the effects of driver factors (age, gender, driving frequency, driving experience) and sign design features (familiarity, concreteness, simplicity, meaningfulness, semantic closeness) on the comprehensibility of traffic signs, finding that motorists were able to better understand the meaning of traffic signs which were familiar, simple, meaningful, and associated with underlying concepts [16,17]. Generally, too much information provided by traffic signs and road markings may increase driver's visual load and negatively affect driving performance $[18,19]$. Too little information may also be a problem, as drivers need more time to make decisions in a complex driving environment and must rely more on their own driving experience [20]. Overall, existing literature focused more on the effects of stand-alone traffic signs and road markings rather than components of an integrated system.

When driving through a roundabout, the surrounding environment will rotate to a certain extent in the driver's view and the rotation of visual cues will vary with the change of viewing angles. Therefore, drivers need mental rotation ability to identify the exit they want. Mental rotation is the ability to rotate an object in one's mind and is an essential paradigm for spatial ability. Shepard and Metzler first introduced the concept of mental rotation in a remarkably elegant experiment in which participants were presented with two images of cubes and asked to determine whether the right image was a rotation or mirror of the left [21]. The experimental results clearly supported that participants' reaction time increased linearly as the angular difference between the two cubes increased. There is evidence indicating that gender and age differences exist in mental rotation abilities. Males and younger adults typically outperform females and older adults on spatial perception tasks [22]. Although human mental rotation ability has a certain capacity [23], mental rotation performance can be improved by training which focuses on practicing with spatial tasks and materials. Attentive visual references can also contribute to the improvement of mental rotation abilities [24,25].

Perceptual constancy is a phenomenon in which an object is seen in the same way under varying circumstances [26]. For example, color constancy is a form of perceptual constancy which ensures that the perceived color of an object remains similar under varying illumination conditions. Similarly, shape constancy is the tendency to perceive an object as having a relatively constant shape regardless of its orientation or the viewing angle. Moreover, color and shape are dominant visual features of traffic signs and road markings and can provide key information that drivers need to process when driving along the road [27]. Therefore, color constancy and shape constancy can be used to mitigate the rotation of visual cues under varying conditions and improve the driver's mental rotation ability and sense of direction.

Installing guide signs and pavement markings is a simple and low-cost solution that can reduce visual load and improve sense of direction. Considering color constancy and shape constancy, a continuous and gradual guide sign system was proposed to improve the safety and efficiency of roundabout operations. Then, a driving simulator was used to quantitatively analyze the effect of this guide sign system on drivers' mental rotation ability. The guide sign system proposed in this paper is expected to provide a reference guide for the effective design of guide sign in complex roundabouts.

\section{Method}

\subsection{Driving Simulator}

As an alternative to on-road experiment, the driving simulator has several advantages. First, the driving performance under different driving conditions can be safely evaluated with the help of the driving simulator. Moreover, the simulator can reliably control and replicate specific driving scenarios and conditions. The simulation experiment was conducted in a virtual reality-based driving simulator, which was developed by the Wuhan University of Technology ITS Research Center (Figure 1). In order to give participants a highly immersive experience, the visual system consisted of three LED 
screens providing a 120-degree forward field of view and three LED screens serving as external and interior rear-view mirrors. Moreover, the simulator could also produce engine and tire squeal sound effects in real time. Participants used an authentic steering wheel, gear stick, and pedals with force feedback to control the simulator. Using the three degree-of-freedom (DOF) motion driving simulator, driving-related data (such as ID, speed, acceleration, latitude and longitude geo-coordinates) was collected at a frequency of $60 \mathrm{~Hz}$.

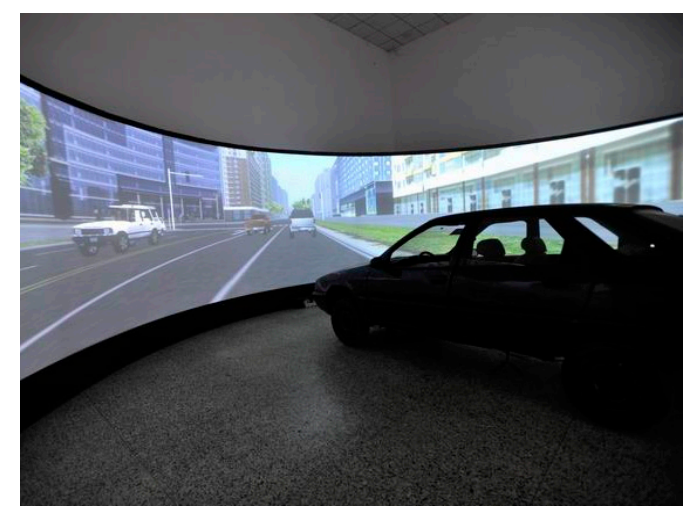

Figure 1. Driving simulator.

\subsection{Participants}

The sample consisted 35 participants, of which 19 were male, representing $54.3 \%$ of the sample, and 16 were female, representing $45.7 \%$ of the sample. Their age ranged from 21 to 45 years (mean = 31.9 and $\mathrm{SD}=7.8$ ), and there were no significant age differences between male and female participants. All participants possessed a valid driver's license, their driving experience (measured in terms of years of licensed driving experience) ranged from 1 to 25 years (mean $=10.5$ and $\mathrm{SD}=6.8$ ), and their self-estimated annual driving distance was at least $3000 \mathrm{~km}$. All the participants had normal or corrected-to-normal vision. Table 1 shows the details of participants.

Table 1. Details of participants.

\begin{tabular}{ccc}
\hline & $N$ & Percent (\%) \\
\hline Gender & & \\
Male & 19 & 54.3 \\
Female & 16 & 45.7 \\
\hline Age & & \\
\hline$[21-30]$ & 16 & 45.7 \\
{$[31-40]$} & 13 & 37.1 \\
{$[41-45]$} & 6 & 17.2 \\
\hline Years of licensed driving experience & & \\
\hline$[1-3]$ & 8 & 22.9 \\
{$[4-6]$} & 12 & 34.3 \\
{$[7-10]$} & 7 & 20.0 \\
{$[11-25]$} & 8 & 22.8 \\
\hline
\end{tabular}

\subsection{Scenarios}

Simulation scenarios consisted of a standard scenario and an optimized scenario. The standard scenario was created according to the Qingnian Road Roundabout in Wuhan, China (Figure 2a), and the optimized scenario was an improved design of guide signs and pavement markings for the roundabout (Figure 2b). The driving simulation scenarios were developed by Autodesk 3ds Max, which provided 
a comprehensive solution to 3D modeling and simulation. The V-ray rendering engine was used to offer high dynamic range textures and create an immersive simulation experience. The urban roads in the simulation scenarios were four-lane divided roadways with two lanes in each direction. According to the Code for Design of Urban Road Engineering, an urban road with a design speed of $40 \mathrm{~km} / \mathrm{h}$ should have a median strip width of $1 \mathrm{~m}$, a lane width of $3.5 \mathrm{~m}$, and a curb width of $0.5 \mathrm{~m}$ [28].

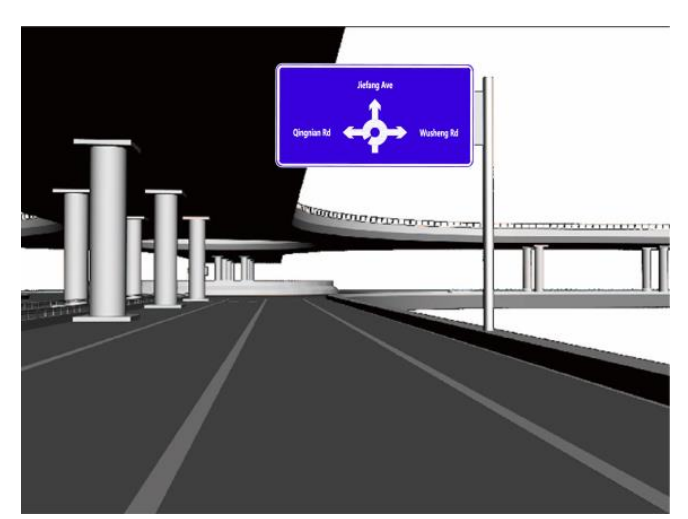

(a) Standard scenario

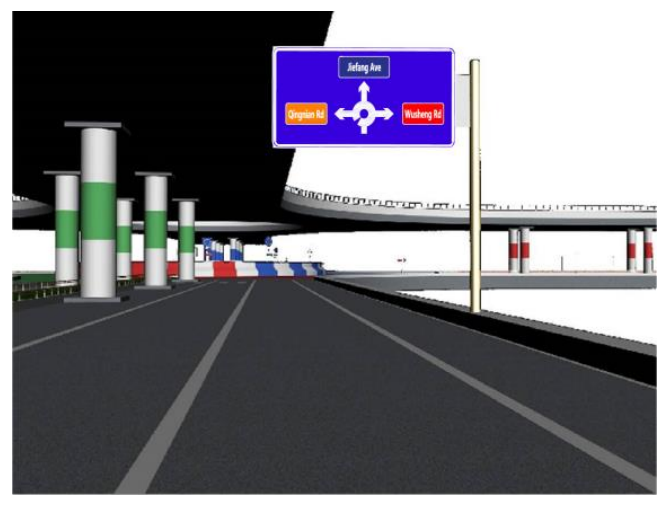

(b) Optimized scenario

Figure 2. Simulation scenarios.

Considering color constancy and shape constancy, a continuous and gradual guide sign system was proposed to improve safety and efficiency of roundabout operations. The designs of traffic signs and pavement markings meet related specification requirements (Code for Layout of Urban Road Traffic Sign and Markings) [29], as shown in Figure 3 and Table 2.

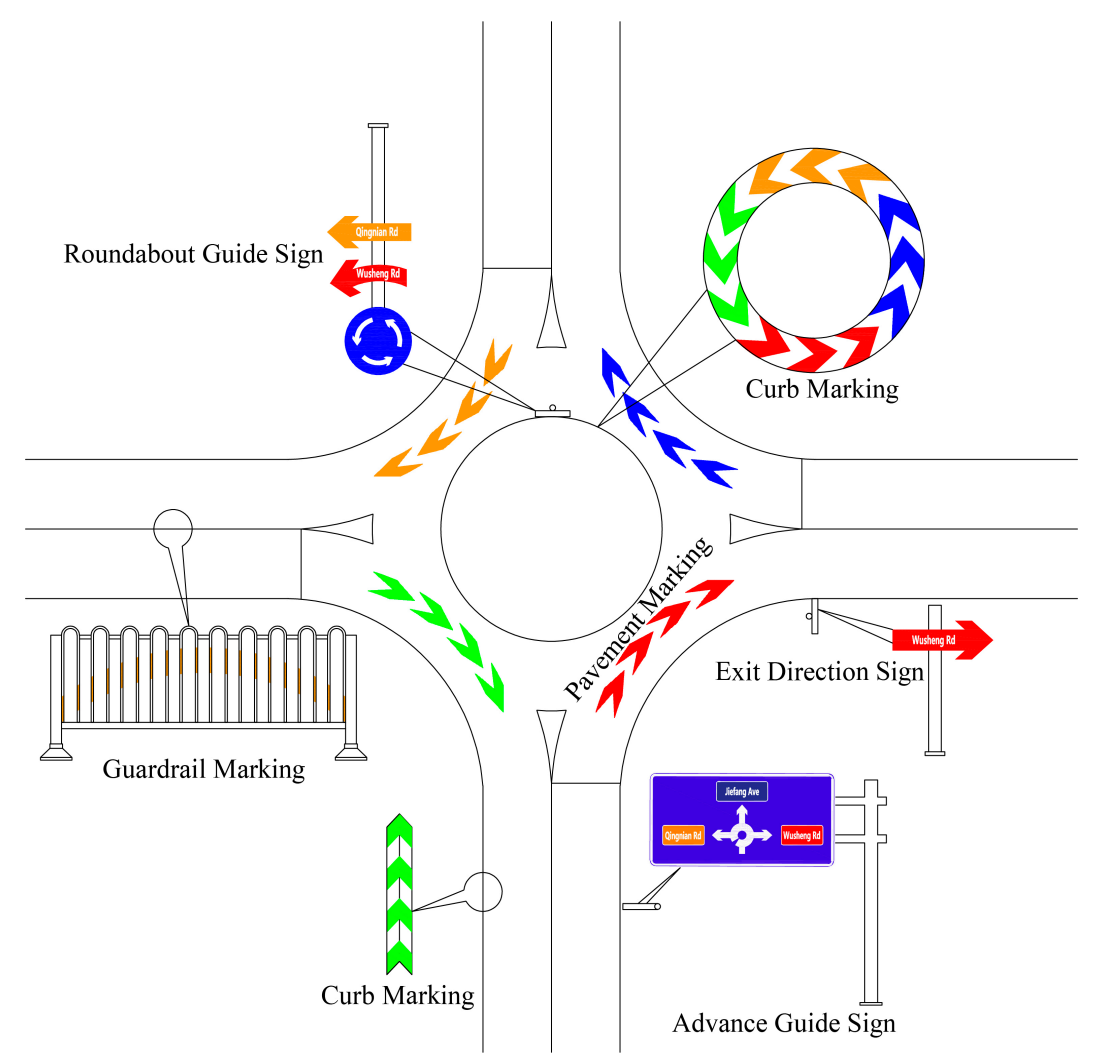

Figure 3. Improved design of guide sign system. 
Table 2. Design parameters of guide sign system.

\begin{tabular}{|c|c|c|c|}
\hline & Treatment & Type of Reflective Material & Color \\
\hline \multirow{3}{*}{ Sign } & Advance guide sign & Diamond grade reflective film & \multirow{6}{*}{$\begin{array}{l}\text { Treatments in different directions } \\
\text { have different colors, and colors are } \\
\text { the same in the same direction. }\end{array}$} \\
\hline & Roundabout guide sign & High-strength grade reflective film & \\
\hline & Exit direction sign & High-strength grade reflective film & \\
\hline \multirow{3}{*}{ Marking } & Pavement marking & Reflective marking & \\
\hline & Curb marking & Reflective marking & \\
\hline & Guardrail marking & Reflective marking & \\
\hline
\end{tabular}

The 3D driving simulation models are approximate imitations of specific on-road driving situations, and they never exactly imitate real driving. Therefore, the simulation model developed in this paper should be verified and validated. Comparative experiments were carried out to validate the simulation model on the driving simulator platform. The simulated driving scene (Figure 2a) was compared to a real driving scene (Figure 4) to ascertain whether there were significant differences between them [30]. The results indicated that travel speed in the simulated driving scene was $34.8 \mathrm{~km} / \mathrm{h}$, and travel speed in the real driving scene was $36.1 \mathrm{~km} / \mathrm{h}$. The results of one sample t-test proved that there was no significant difference between the simulated driving scene and real driving scene (Table 3).

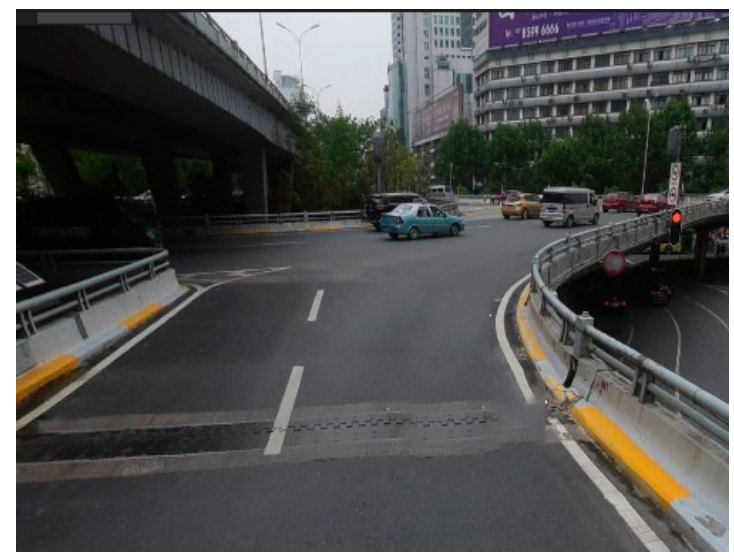

Figure 4. Real driving scene.

Table 3. One sample t-test.

\begin{tabular}{|c|c|c|c|c|c|}
\hline & \multicolumn{5}{|c|}{ Test Value $=36.1 \mathrm{~km} / \mathrm{h}($ Travel Speed in the Real Driving Scene $)$} \\
\hline & \multirow[t]{2}{*}{$N$} & \multirow[t]{2}{*}{$p$-Value } & \multirow[t]{2}{*}{ Mean $(\mathbf{k m} / \mathbf{h})$} & \multicolumn{2}{|c|}{$\begin{array}{l}95 \% \text { Confidence Interval of } \\
\text { the Difference }\end{array}$} \\
\hline & & & & Lower & Upper \\
\hline $\begin{array}{l}\text { Travel speed in the } \\
\text { simulated driving scene }\end{array}$ & 35 & 0.097 & 34.8 & 34.014 & 35.586 \\
\hline
\end{tabular}

\subsection{Procedures}

Participants were provided with information about operation of the driving simulator and procedure of the experiment at the beginning of the experimental session. Then, the participants were allowed to undertake a supervised driving practice (about $15 \mathrm{~min}$ ) in order to familiarize themselves with the driving tasks and scenarios. Each participant was assigned a series of scenarios in a random sequence, and $10 \mathrm{~s}$ of preparation time was reserved before starting the test. Meanwhile, participants were required to take a 3 min break after each scenario run. During each drive, participants drove themselves without distractions. 
The entry and exit were selected by the simulator randomly. Consequently, there were $A_{4}^{2}=12$ permutations for a four-way intersection. The participant was told an exit name randomly before entering the roundabout, and the participant needed to find the exact exit (Figure 5). In order to reduce random errors and improve the reliability of the experiments, each permutation needed to be repeated 10 times for each participant. Two indexes, which consist of accuracy rate and travel time, were used to measure the mental rotation ability. The first index is the proportion of participants who chose the exact exit after exiting the roundabout. The second index is defined as the time needed to drive through the roundabout. After each drive, the travel time and whether the participant chose the right exit were collected by the simulator.

$$
t_{n}=T_{n}^{1}-T_{n}^{2}
$$

where $t_{n}$ is the travel time, $T_{n}^{1}$ is the time when participant $n$ enters the roundabout, and $T_{n}^{2}$ is the time when participant $n$ exits the roundabout.

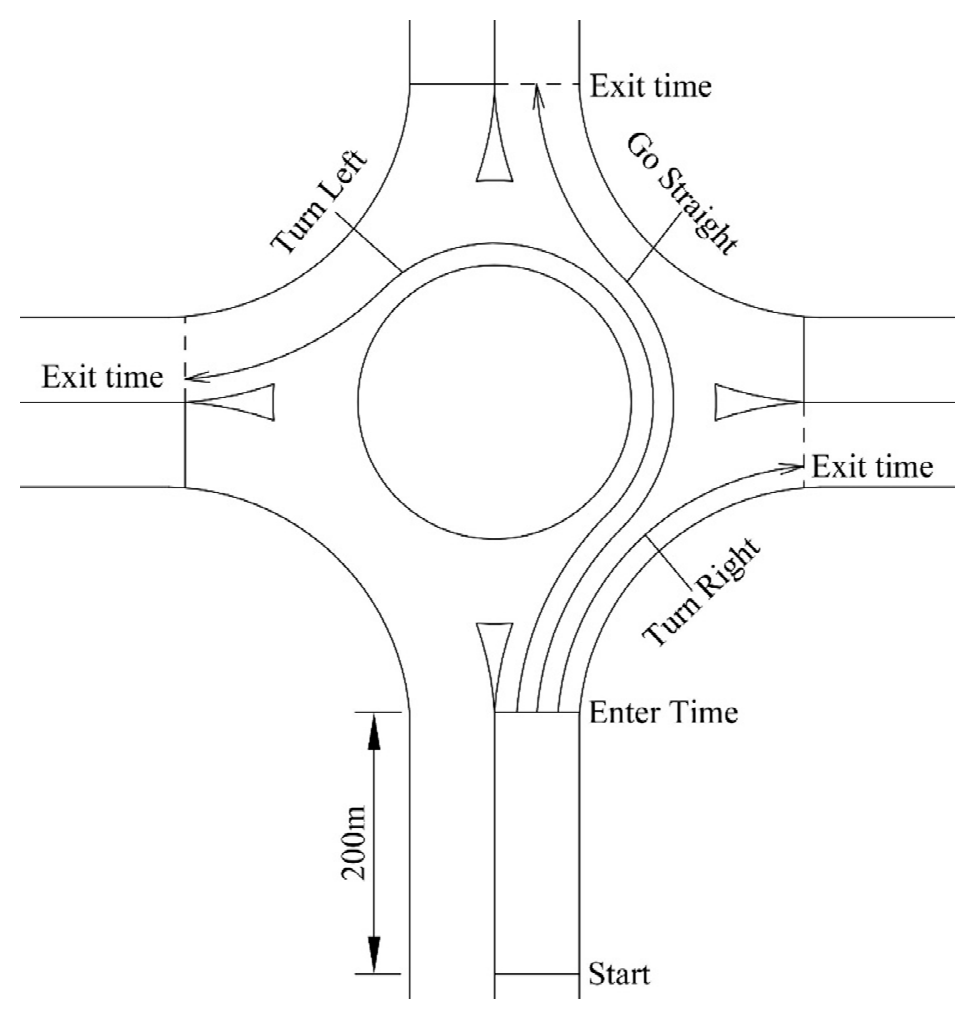

Figure 5. Schematic of tests.

\section{Results}

\subsection{Test Results of Accuracy Rate}

Table 4 and Figure 6 present the relationship between accuracy rate and ages of participants.

Table 4. Relationship between accuracy rate and ages of participants.

\begin{tabular}{cccc}
\hline \multirow{2}{*}{ Age (Year) } & \multicolumn{2}{c}{ Accuracy Rate (\%) } & \multirow{2}{*}{ Improved Rate (\%) } \\
\cline { 2 - 3 } & Standard Scenario & Optimized Scenario & \\
\hline $21-30$ & $75.6 \pm 8.5$ & $93.5 \pm 4.5$ & 23.7 \\
$31-40$ & $70.2 \pm 10.8$ & $89.0 \pm 7.8$ & 26.8 \\
$41-45$ & $60.1 \pm 11.3$ & $85.5 \pm 8.9$ & 42.3 \\
\hline
\end{tabular}




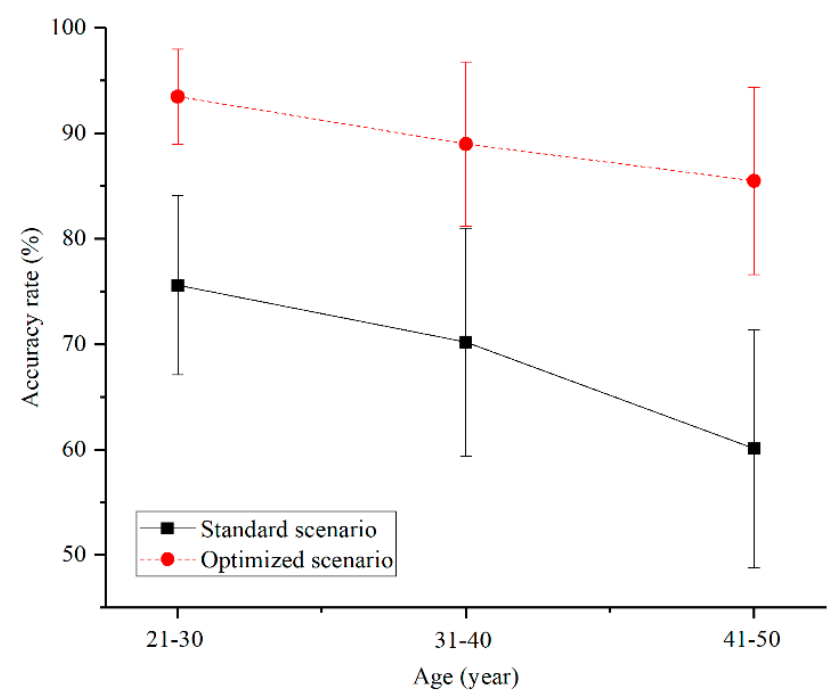

Figure 6. Relationship between accuracy rate and ages of participants.

From Table 4 and Figure 6, the following can be observed:

(1) The guide sign system can improve the accuracy rate significantly $(p=0.017<0.05)$, and the average improved rate is $30.9 \%$.

(2) Overall, the accuracy rate decreases with the increase of ages of participants.

Table 5 and Figure 7 present the relationship between accuracy rate and genders of participants.

Table 5. Relationship between accuracy rate and genders of participants.

\begin{tabular}{ccccc}
\hline \multirow{2}{*}{ Age (Year) } & \multicolumn{4}{c}{ Accuracy Rate (\%) } \\
\cline { 2 - 5 } & \multicolumn{3}{c}{ Male } & \multicolumn{2}{c}{ Female } \\
\cline { 2 - 5 } & Standard Scenario & Optimized Scenario & Standard Scenario & Optimized Scenario \\
\hline $21-30$ & $76.5 \pm 7.8$ & $95.1 \pm 4.2$ & $73.5 \pm 8.9$ & $91.2 \pm 4.7$ \\
$31-40$ & $72.0 \pm 10.6$ & $91.3 \pm 8.1$ & $68.8 \pm 11.0$ & $88.4 \pm 7.2$ \\
$41-45$ & $62.3 \pm 12.2$ & $87.2 \pm 8.8$ & $58.4 \pm 10.4$ & $84.5 \pm 9.2$ \\
Average & 70.3 & 91.2 & 66.9 & 88.0 \\
\hline
\end{tabular}

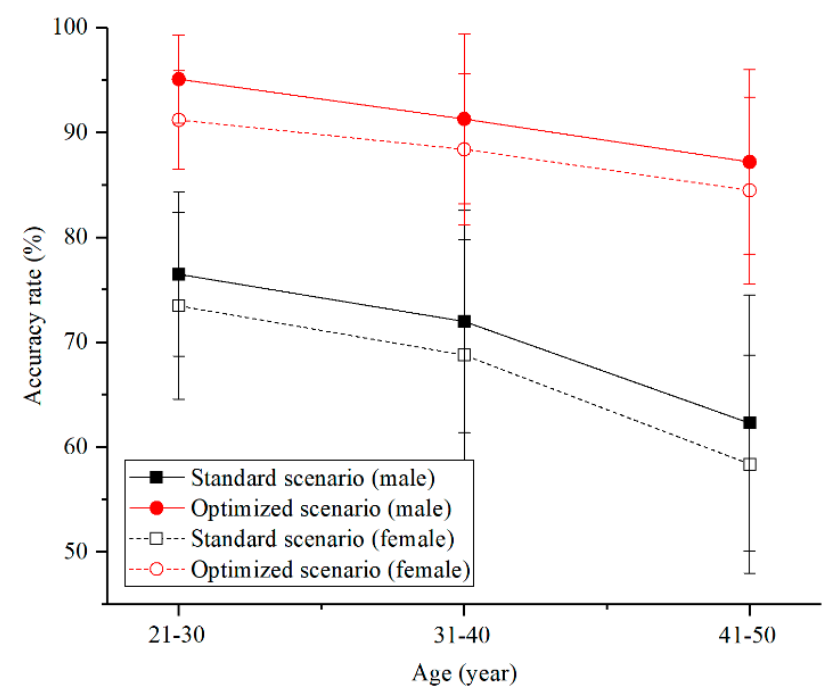

Figure 7. Relationship between accuracy rate and genders of participants.

From Table 5 and Figure 7, the following can be observed: 
(1) In both the standard scenario and optimized scenario, men outperformed women in accuracy rate $(p=0.032<0.05)$.

(2) Overall, the accuracy rate decreases with the increase of ages of participants.

Table 6 and Figure 8 present the relationship between accuracy rate and angle of rotation. The angle of rotation of turn right, go straight, and turn left were defined as $90^{\circ}, 180^{\circ}$, and $270^{\circ}$, respectively.

Table 6. Relationship between accuracy rate and angle of rotation.

\begin{tabular}{cccc}
\hline \multirow{2}{*}{ Angle of Rotation $\left(^{\circ}\right)$} & \multicolumn{2}{c}{ Accuracy Rate (\%) } & \multirow{2}{*}{ Improved Rate (\%) } \\
\cline { 2 - 3 } & Standard Scenario & Optimized Scenario & \\
\hline 90 & $76.3 \pm 9.5$ & $94.4 \pm 4.4$ & 23.7 \\
180 & $73.7 \pm 12.6$ & $92.7 \pm 4.8$ & 25.8 \\
270 & $70.3 \pm 11.7$ & $89.1 \pm 5.4$ & 26.7 \\
\hline
\end{tabular}

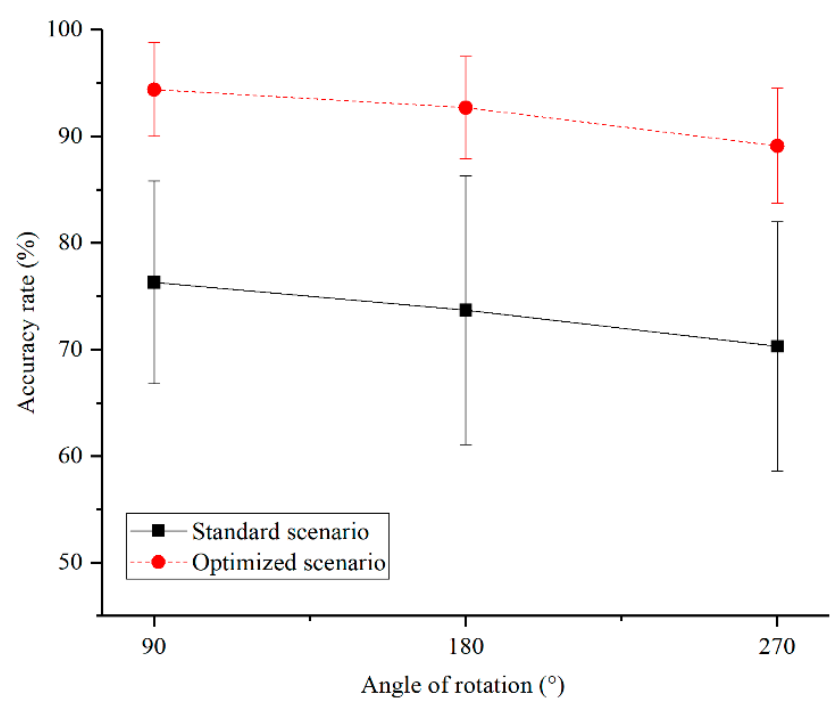

Figure 8. Relationship between accuracy rate and angle of rotation.

From Table 6 and Figure 8, the following can be observed:

(1) The guide sign system can improve accuracy rate significantly $(p=0.021<0.05)$, and the average improved rate is $25.4 \%$.

(2) Overall, the accuracy rate decreases with the increase of angle of rotation.

\subsection{Test Results of Travel Time}

Table 7 and Figure 9 present the relationship between travel time and ages of participants.

Table 7. Relationship between travel time and ages of participants.

\begin{tabular}{cccc}
\hline \multirow{2}{*}{ Age (Year) } & \multicolumn{2}{c}{ Travel Time (s) } & \multirow{2}{*}{ Reduced Rate (\%) } \\
\cline { 2 - 3 } & Standard Scenario & Optimized Scenario & \\
\hline $21-30$ & $9.1 \pm 1.0$ & $7.6 \pm 0.7$ & 16.5 \\
$31-40$ & $9.6 \pm 1.2$ & $8.2 \pm 0.6$ & 14.6 \\
$41-45$ & $10.5 \pm 1.4$ & $9.0 \pm 0.6$ & 14.3 \\
\hline
\end{tabular}




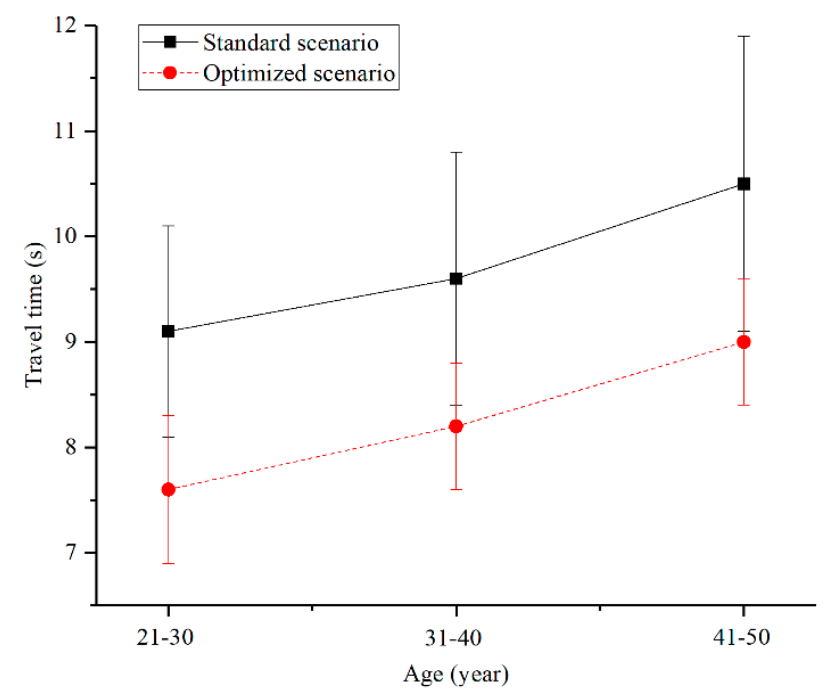

Figure 9. Relationship between travel time and ages of participants.

From Table 7 and Figure 9, the following can be observed:

(1) The guide sign system can reduce the travel time significantly $(p=0.023<0.05)$, and the average reduced rate is $15.1 \%$.

(2) Overall, the travel time increases with the increase of ages of participants.

Table 8 and Figure 10 present the relationship between travel time and genders of participants.

Table 8. Relationship between travel time and genders of participants.

\begin{tabular}{ccccc}
\hline \multirow{2}{*}{ Age (Year) } & \multicolumn{4}{c}{ Travel Time (s) } \\
\cline { 2 - 5 } & \multicolumn{3}{c}{ Male } & \multicolumn{2}{c}{ Female } \\
\cline { 2 - 5 } & Standard Scenario & Optimized Scenario & Standard Scenario & Optimized Scenario \\
\hline $21-30$ & $8.6 \pm 1.0$ & $7.2 \pm 0.5$ & $9.5 \pm 0.8$ & $8.1 \pm 0.6$ \\
$31-40$ & $9.1 \pm 1.1$ & $7.8 \pm 0.6$ & $10.1 \pm 1.0$ & $8.6 \pm 0.8$ \\
$41-45$ & $10.0 \pm 1.5$ & $8.6 \pm 0.8$ & $10.9 \pm 1.1$ & $9.4 \pm 0.7$ \\
Average & 9.2 & 7.9 & 10.2 & 8.7 \\
\hline
\end{tabular}

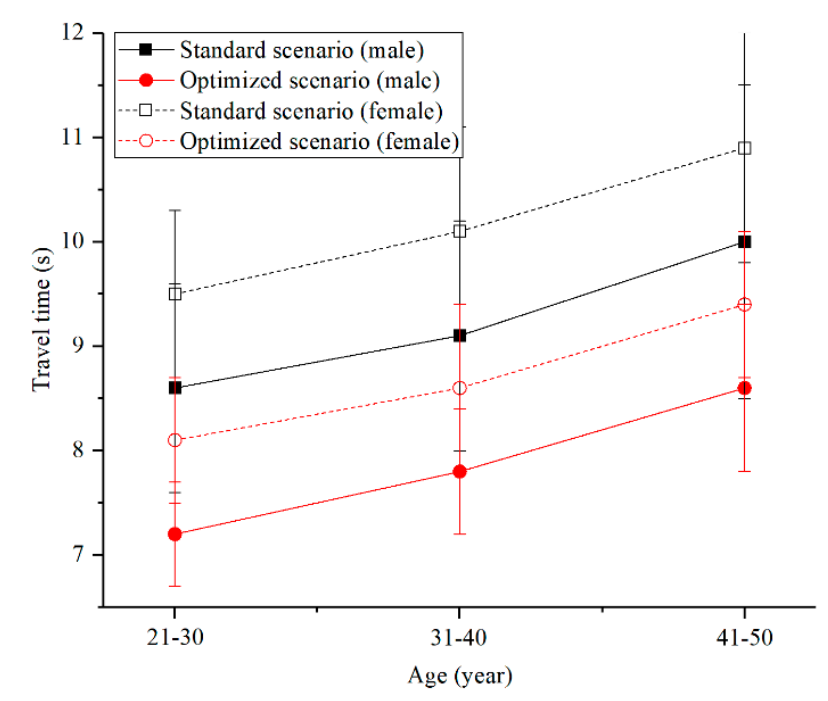

Figure 10. Relationship between travel time and genders of participants.

Table 8 and Figure 10, the following can be observed: 
(1) In both the standard scenario and optimized scenario, the travel time of the males is shorter than that of the females $(p=0.014<0.05)$.

(2) Overall, the travel time increases with the increase of ages of participants.

Since turn right, go straight, and turn left had different travel distances, the travel speed was used to normalize data instead of travel time. Table 9 and Figure 11 present the relationship between travel speed and angle of rotation.

Table 9. Relationship between travel speed and angle of rotation.

\begin{tabular}{cccc}
\hline \multirow{2}{*}{ Angle of Rotation $\left({ }^{\circ}\right)$} & \multicolumn{2}{c}{ Travel Speed $\mathbf{~ ( k m / h )}$} & \multirow{2}{*}{ Improved Rate (\%) } \\
\cline { 2 - 3 } & Standard Scenario & Optimized Scenario & \\
\hline 90 & $37.0 \pm 2.7$ & $42.1 \pm 2.8$ & 13.8 \\
180 & $35.2 \pm 3.6$ & $40.7 \pm 3.4$ & 15.6 \\
270 & $31.8 \pm 4.5$ & $37.5 \pm 4.2$ & 17.9 \\
\hline
\end{tabular}

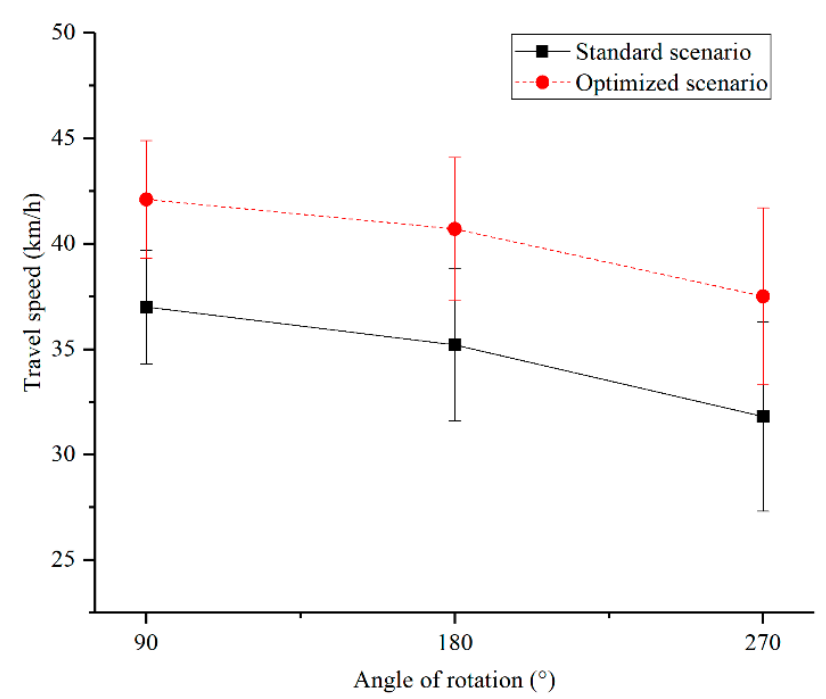

Figure 11. Relationship between travel speed and angle of rotation.

From Table 9 and Figure 11, the following can be observed:

(1) The guide sign system can improve travel speed significantly $(p=0.025<0.05)$, and the average improved rate is $15.8 \%$.

(2) Overall, the travel speed decreases with the increase of angle of rotation.

\section{Discussion}

Reaction time reveals the speed of the decision-making process [31]. Generally, a shorter reaction time indicates that visual recognition of traffic signs and road markings is easier, and also means that drivers can better understand and interpret the meanings of these road traffic control devices. Moreover, reducing reaction time can increase sensitivity to speed variation and leave more time for drivers to deal with emergencies, which is beneficial to driving safety. Since efficiently obtaining detailed reaction time data from the simulator was difficult, travel time was used to investigate the visual load of traffic signs and road markings instead of reaction time. However, reduced travel time or increased travel speed does not mean that it is beneficial for traffic safety. Further research is required to obtain reaction time data, which is essential to shed light on the detailed recognition process of traffic signs and road markings. Additionally, driving through an intersection may involve a complex pathfinding process, which has a certain impact on visual load and reaction time. Therefore, an eye-tracking system is needed to obtain eye movement characteristics and explore the specific 
pathfinding process, which will be helpful to comprehensively assess the reasonability and feasibility of the proposed guide sign system.

In order to assess mental rotation ability, notable research required participants to compare the parity of two three-dimensional block figures, which were presented in different spatial orientations. The reaction time increased linearly with the angular disparity between two figures. The results implied that participants simulated an actual rotation to align the two figures or to rotate the character into an upright orientation [21]. Moreover, mental rotation tasks commonly revealed gender and age differences, as males and younger drivers generally performed more rapidly and accurately [32]. In the present study, the driving simulator experiments reached similar conclusions. However, as the participants accumulated greater driving distances in the simulator, they became familiar with the driving scenarios [33]. This type of familiarity could improve the accuracy of exit identification and reduce the travel time driving through a roundabout. Despite this, the proposed guide sign system could dramatically improve drivers' mental rotation ability and sense of direction.

This paper used a case study approach to explore the effects of proposed guide sign system on traffic operation and safety performance at roundabouts. Future research should investigate the generalizability and transferability of these findings related to the design of traffic signs and road markings under varying conditions, such as poor lighting conditions, different traffic conditions, various weather conditions, different types of roundabouts, and different combinations of variables. Moreover, these findings should be validated by on-road driving tests.

\section{Conclusions}

The purpose of this paper was to propose a simple and low-cost method using traffic signs and pavement markings to improve the safety and efficiency of roundabout operations rather than relying only on road reconstruction. Using color constancy and shape constancy, a continuous and gradual guide sign system was developed for complex roundabouts which lacked ambient visual guidance. The driving simulator experiments were conducted to evaluate the effects of this guide sign system on driving performance. The results indicated that the guide sign system can effectively improve the accuracy of exit identification and reduce the travel time driving through a roundabout despite the gender and age differences among drivers. The guide sign system can improve drivers' sense of direction and mental rotation ability, which are beneficial to safety performance, delay reduction, and the efficiency improvement of roundabouts. Overall, this paper provides a promising approach for future practice of traffic signs and road markings in a complex roundabout.

Author Contributions: All authors contributed to the conceptualization of this paper, as well as the methodology and data analysis. H.W. mainly focused on the writing, review and editing of the paper, while X.C. and Z.D. provided the experimentation platform and financial support.

Funding: This research was sponsored by the National Natural Science Foundation of China (No. 51578433 and No. 71734004).

Conflicts of Interest: The authors declare no conflict of interest.

\section{References}

1. Várhelyi, A. The effects of small roundabouts on emissions and fuel consumption: A case study. Transp. Res. Part D Transp. Environ. 2002, 7, 65-71. [CrossRef]

2. Gross, F.; Lyon, C.; Persaud, B.; Srinivasan, R. Safety effectiveness of converting signalized intersections to roundabouts. Accid. Anal. Prev. 2013, 50, 234-241. [CrossRef] [PubMed]

3. Mauro, R.; Branco, F. Comparative analysis of compact multilane roundabouts and turbo-roundabouts. Transp. Eng. 2009, 136, 316-322. [CrossRef]

4. Costa, M.; Simone, A.; Vignali, V.; Lantieri, C.; Bucchi, A.; Dondi, G. Looking behavior for vertical road signs. Transp. Res. Part F Traffic Psychol. Behav. 2014, 23, 147-155. [CrossRef]

5. Borowsky, A.; Shinar, D.; Parmet, Y. Sign location, sign recognition, and driver expectancies. Transp. Res. Part F Traffic Psychol. Behav. 2008, 11, 459-465. [CrossRef] 
6. Shinar, D.; Vogelzang, M. Comprehension of traffic signs with symbolic versus text displays. Transp. Res. Part F Traffic Psychol. Behav. 2013, 18, 72-82. [CrossRef]

7. Trick, L.M.; Toxopeus, R.; Wilson, D. The effects of visibility conditions, traffic density, and navigational challenge on speed compensation and driving performance in older adults. Accid. Anal. Prev. 2010, 42, 1661-1671. [CrossRef]

8. Martens, M.H.; Fox, M.R. Do familiarity and expectations change perception? Drivers' glances and response to changes. Transp. Res. Part F Traffic Psychol. Behav. 2007, 10, 476-492. [CrossRef]

9. Lai, C.J. Drivers' comprehension of traffic information on graphical route information panels. Accid. Anal. Prev. 2012, 45, 565-571. [CrossRef]

10. Shalloe, S.; Sharples, S.C.; Burnett, G.; Crundall, D.; Meekums, R.; Morris, D. Developing a graphical route information panel (GRIP) for use on the UK motorway network. The first steps. Transp. Res. Part F Traffic Psychol. Behav. 2014, 27, 133-149. [CrossRef]

11. Castro, C.; Moreno-Ríos, S.; Tornay, F.; Vargas, C. Mental representations of obligatory and prohibitory traffic signs. Acta Psychol. 2008, 129, 8-17. [CrossRef] [PubMed]

12. Zhao, X.; Wu, Y.; Rong, J.; Ma, J. The effect of chevron alignment signs on driver performance on horizontal curves with different roadway geometries. Accid. Anal. Prev. 2015, 75, 226-235. [CrossRef] [PubMed]

13. Al-Madani, H.; Al-Janahi, A.R. Assessment of drivers' comprehension of traffic signs based on their traffic, personal and social characteristics. Transp. Res. Part F Traffic Psychol. Behav. 2002, 5, 63-76. [CrossRef]

14. Ben-Bassat, T.; Shinar, D. Ergonomic guidelines for traffic sign design increase sign comprehension. Hum. Factors 2006, 48, 182-195. [CrossRef] [PubMed]

15. Liu, B.; Wang, Z.; Song, G.; Wu, G. Cognitive processing of traffic signs in immersive virtual reality environment: An ERP study. Neurosci. Lett. 2010, 485, 43-48. [CrossRef] [PubMed]

16. Ng, A.W.; Chan, A.H. The guessability of traffic signs: Effects of prospective-user factors and sign design features. Accid. Anal. Prev. 2007, 39, 1245-1257. [CrossRef] [PubMed]

17. $\mathrm{Ng}, \mathrm{A} . \mathrm{W}$; C Chan, A.H. The effects of driver factors and sign design features on the comprehensibility of traffic signs. J. Saf. Res. 2008, 39, 321-328. [CrossRef]

18. Metz, B.; Krüger, H.P. Do supplementary signs distract the driver? Transp. Res. Part F Traffic Psychol. Behav. 2014, 23, 1-14. [CrossRef]

19. Kaplan, S.; Bortei-Doku, S.; Prato, C.G. The relation between the perception of safe traffic and the comprehension of road signs in conditions of ambiguous and redundant information. Transp. Res. Part F Traffic Psychol. Behav. 2018, 55, 415-425. [CrossRef]

20. Marti, G.; Morice, A.H.; Montagne, G. Drivers' decision-making when attempting to cross an intersection results from choice between affordances. Front. Hum. Neurosci. 2015, 8, 1026. [CrossRef]

21. Shepard, R.N.; Metzler, J. Mental rotation of three-dimensional objects. Science 1971, 171, 701-703. [CrossRef] [PubMed]

22. Geiser, C.; Lehmann, W.; Eid, M. A note on sex differences in mental rotation in different age groups. Intelligence 2008, 36, 556-563. [CrossRef]

23. Xu, Y.; Franconeri, S.L. Capacity for visual features in mental rotation. Psychol. Sci. 2015, 26, 1241-1251. [CrossRef] [PubMed]

24. Cheng, Y.L.; Mix, K.S. Spatial training improves children's mathematics ability. J. Cogn. Dev. 2014, 15, 2-11. [CrossRef]

25. Moè, A. Teaching motivation and strategies to improve mental rotation abilities. Intelligence 2016, 59, 16-23. [CrossRef]

26. Matthen, M. The Oxford Handbook of Philosophy of Perception; Oxford University Press: Oxford, UK, 2015.

27. Gao, X.W.; Podladchikova, L.; Shaposhnikov, D.; Hong, K.; Shevtsova, N. Recognition of traffic signs based on their colour and shape features extracted using human vision models. J. Vis. Commun. Image Represent. 2006, 17, 675-685. [CrossRef]

28. Ministry of Housing and Urban-Rural Development of the People's Republic of China (MOHURD). Code for Design of Urban Road Engineering; China Architecture \& Building Press: Beijing, China, 2012.

29. Ministry of Housing and Urban-Rural Development of the People's Republic of China (MOHURD). Code for Layout of Urban Road Traffic Sign and Markings; China Planning Press: Beijing, China, 2015.

30. Wan, H.; Du, Z.; Ran, B.; Wang, M. Speed control method for highway tunnel safety based on visual illusion. Transp. Res. Rec. 2015, 2485, 1-7. [CrossRef] 
31. Mayhew, D.R.; Simpson, H.M.; Wood, K.M.; Lonero, L.; Clinton, K.M.; Johnson, A.G. On-road and simulated driving: Concurrent and discriminant validation. J. Saf. Res. 2011, 42, 267-275. [CrossRef]

32. Voyer, D.; Voyer, S.; Bryden, M.P. Magnitude of sex differences in spatial abilities: A meta-analysis and consideration of critical variables. Psychol. Bull. 1995, 117, 250. [CrossRef]

33. Castro, C.; Horberry, T. The Human Factors of Transport Signs; CRC Press: Boca Raton, FL, USA, 2004.

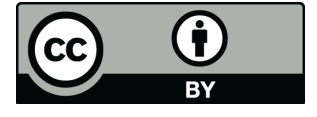

(C) 2019 by the authors. Licensee MDPI, Basel, Switzerland. This article is an open access article distributed under the terms and conditions of the Creative Commons Attribution (CC BY) license (http://creativecommons.org/licenses/by/4.0/). 